\title{
Symptomatic abnormalities of dark adaptation in patients with age-related Bruch's membrane change
}

\author{
Robert L Steinmetz, Robert Haimovici, Chris Jubb, Frederick W Fitzke, Alan C Bird
}

\begin{abstract}
Some patients with age-related changes at the level of Bruch's membrane and good visual acuity report poor vision in dim light, fading vision in bright light, and a central scotoma noticeable in the dark. Ophthalmic examination, scotopic thresholds, and dark adaptation kinetics were recorded in 12 eyes of 12 patients with such symptoms. All had macular drusen which were hypofluorescent on fluorescein angiography in nine subjects, and six had evidence of prolonged choroidal filling on fluorescein angiography. Scotopic thresholds were depressed in six patients who all experienced a central scotoma in the dark or poor night vision. The kinetics of dark adaptation were abnormal in all 10 patients in whom reliable measurements were possible. The findings suggest that visual symptoms reflect abnormality of both scotopic sensitivity and the time course of dark adaptation in patients with age-related Bruch's membrane change. (Br f Ophthalmol 1993; 77: 549-554)
\end{abstract}

Loss of visual acuity in age-related macular degeneration is usually attributed to geographic atrophy, choroidal neovascularisation, or retinal pigment epithelial detachment. Visual deficits in the absence of these events are less well recognised. ${ }^{1}$ It is evident that some patients describe visual symptoms despite good acuity and few ophthalmoscopic changes of age-related macular disease other than drusen. These deficits vary under different levels of illumination but cannot be attributed to intraocular light scattering from corneal or lens opacities or pupillary abnormalities. Some patients report worsening vision after several minutes in bright sunlight or slowed recovery after exposure to bright light. Others had good vision in bright light but with visual difficulties in dim illumination. A central scotoma noticed in the dark is also described. Abnormal dark adaptation has been recorded previously in patients with age-related macular degeneration..$^{2-6}$ In these reports, however, no correlation was sought between the abnormalities recorded and visual symptoms. We performed scotopic threshold perimetry and dark adaptometry in 12 consecutive patients with macular drusen and good acuity in order to identify whether or not the symptoms reflected measurable functional deficit.

\section{Patients and methods}

Patients with age-related maculopathy seen in the retinal diagnostic department at Moorfields eye hospital were asked a series of questions pertaining to their visual function at different light levels, and were asked to return for psychophysical testing if they had symptoms which could not be readily accounted for by the examination findings. Patients were excluded if their corrected visual acuity was worse than $6 / 12$, there was greater than 1 dioptre of correction, or there was retinal pigment epithelial detachment, serous retinal detachment, subretinal neovascularisation, geographic atrophy, a history of intraocular inflammation, surgery, glaucoma, cataract, or diabetes mellitus, or if they were unable or unwilling to take part in the study. No patient included in this study had a history of hepatic or biliary cirrhosis, chronic bowel disease, protein calorie malnutrition, or sickle cell anaemia, conditions which are known to cause abnormal dark adaptation. ${ }^{711}$ In addition to complete ophthalmic examination and psychophysical testing, patients underwent fundus photography and fluorescein angiography. A group of people matched by age and sex who had no clinical evidence of Bruch's membrane change and who were asymptomatic served as a comparison group. All subjects gave informed consent, and the study was approved by the ethical committee of Moorfields Eye Hospital.

The eye with the best measured visual acuity was selected for psychophysical testing. A pupillary diameter of at least $6 \mathrm{~mm}$ was achieved by instilling one drop of $2.5 \%$ phenylephrine, and $1 \%$ cyclopentolate. Patients were placed in a dark room for 45 minutes. No significant differences in dilated pupil size were noted between our study patients and an age-matched comparison group. Testing was performed without spectacle correction to eliminate variables such as spectacle tint, thickness, base curve, and reflections. ${ }^{+}$The fellow eye was patched for all testing.

A Humphrey field analyser (San Leandro, CA) modified for use under scotopic conditions was used to perform static perimetry with the 30-2 programme. ${ }^{1213}$ The patient was seated at the Field Analyzer with head position controlled by a chin and forehead rest $30 \mathrm{~cm}$ from the target, and was instructed to look at the red fixation light. An infrared source illuminated the bowl, and an infrared CCD camera (Philips, Einthoven, Holland) was used to monitor eye movements. With the background illumination turned off, a stimulus of wavelength $450 \mathrm{~nm}$, duration 0.5 seconds, and Goldmann $V$ size was used to perform threshold static. Five patients (Nos 4, 6, 8, 11, 13) also underwent dark adapted threshold testing with a red stimulus produced using a $608 \mathrm{~nm}$ cut off filter. Goldmann size III and $\mathrm{V}$ stimuli were also used to determine dark adapted thresholds at two retinal locations selected for further study of the dark adaptation. 
Table 1 Clinical details of subjects. Case 5 did not have fluorescein angiography

\begin{tabular}{|c|c|c|c|c|c|c|c|}
\hline \multirow[b]{2}{*}{ Case } & \multirow[b]{2}{*}{ Age } & \multirow[b]{2}{*}{ Sex } & \multirow[b]{2}{*}{ Symptoms } & \multirow{2}{*}{$\begin{array}{l}\text { Visual } \\
\text { acuity }\end{array}$} & \multicolumn{2}{|l|}{ Study eye } & \multirow[b]{2}{*}{ Fellow eye } \\
\hline & & & & & Drusen & PCFC & \\
\hline 1 & 78 & $\mathbf{F}$ & poor vision & $6 / 9$ & discrete & no & pigment epithelial \\
\hline 2 & 73 & $\mathbf{M}$ & $\begin{array}{l}\text { poor vision } \\
\text { in bright light }\end{array}$ & $6 / 6$ & $\begin{array}{l}\text { confluent } \\
\text { hypofluorescent }\end{array}$ & yes & disciform scar \\
\hline 3 & 76 & $\mathbf{F}$ & $\begin{array}{l}\text { central scotoma } \\
\text { in the dark }\end{array}$ & $6 / 6$ & $\begin{array}{l}\text { confluent } \\
\text { hypofluorescent }\end{array}$ & yes & disciform scar \\
\hline 4 & 54 & $\mathbf{M}$ & $\begin{array}{l}\text { poor night vision, } \\
\text { slow DA }\end{array}$ & $6 / 6$ & $\begin{array}{l}\text { discrete } \\
\text { hypofluorescent }\end{array}$ & yes & disciform scar \\
\hline 5 & 86 & $\mathbf{F}$ & $\begin{array}{l}\text { central scotoma } \\
\text { in the dark }\end{array}$ & $6 / 6$ & discrete & - & disciform scar \\
\hline 6 & 71 & $\mathbf{M}$ & $\begin{array}{l}\text { poor vision } \\
\text { in bright light }\end{array}$ & $6 / 6$ & $\begin{array}{l}\text { confluent } \\
\text { hypofluorescent }\end{array}$ & yes & drusen \\
\hline 7 & 55 & $\mathbf{M}$ & $\begin{array}{l}\text { poor night vision } \\
\text { slow DA }\end{array}$ & $6 / 9$ & $\begin{array}{l}\text { subconfluent } \\
\text { hyperfluorescent }\end{array}$ & no & drusen \\
\hline 8 & 76 & $\mathbf{M}$ & poor night vision & $6 / 12$ & $\begin{array}{l}\text { discrete } \\
\text { hypofluorescent }\end{array}$ & no & drusen \\
\hline 9 & 80 & $\mathbf{M}$ & $\begin{array}{l}\text { central scotoma } \\
\text { in the dark }\end{array}$ & $6 / 9$ & $\begin{array}{l}\text { subconfluent } \\
\text { hypofluorescent }\end{array}$ & yes & drusen \\
\hline 10 & 76 & $\mathbf{F}$ & $\begin{array}{l}\text { poor vision in } \\
\text { bright light, } \\
\text { central scotoma } \\
\text { in the dark }\end{array}$ & $6 / 12$ & $\begin{array}{l}\text { discrete } \\
\text { hypofluorescent }\end{array}$ & yes & drusen \\
\hline 11 & 71 & $\mathbf{F}$ & slow DA & $6 / 9$ & $\begin{array}{l}\text { subconfluent } \\
\text { hypofluoresent }\end{array}$ & no & disciform scar \\
\hline 12 & 80 & $\mathbf{M}$ & $\begin{array}{l}\text { central scotoma } \\
\text { in the dark }\end{array}$ & $6 / 9$ & $\begin{array}{l}\text { discrete } \\
\text { hyperfluorescent }\end{array}$ & yes & disciform scar \\
\hline
\end{tabular}

$\mathrm{PCFP}=$ prolonged choroidal filling phase

$\mathrm{DA}=$ dark adaptation
This was performed on the Humphrey field analyser controlled by an external computer. ${ }^{13}$ Usually, one curve was performed at a location with normal final sensitivity, and one within an area of decreased sensitivity, when this was present. A 2 minute period of light adaptation (equivalent to 7.5 scotopic troland seconds), sufficient to bleach more than $95 \%$ of the available rhodopsin, was achieved using lamps installed in the Humphrey perimeter. If necessary, the patient's eyelids were held open gently by the examiner. The testing strategy used a method of ascending limits in which the stimulus was presented at 3.5 second intervals, and after each response the stimulus intensity for each location was reduced by $7 \mathrm{~dB}$ for the first three responses and $3 \mathrm{~dB}$ for subsequent responses. They were then increased by $1 \mathrm{~dB}$ until the next response was recorded.

Data from age-matched normal eyes served as comparison for perimetry and dark adaptation curves. Dark adapted thresholds were considered abnormal if there was a $10 \mathrm{~dB}$ or greater elevation when compared with age-matched controls tested in a similar manner. The outermost location on the 30-2 programme and the two locations above and below the blind spot were excluded from this analysis. The rod cone break was determined by visual inspection. Datum points after this time were used to determine the time constant of rhodopsin regeneration using curve fitting software, and an equation of the form $\log (\mathrm{I})=\mathrm{A}+\mathrm{B}$ (e) ${ }^{r-(v c)]} \cdot{ }^{14}$ Return of prebleach sensitivity was defined as the time at which the average of the last five measurements came within $5 \mathrm{~dB}$ of the average of the prebleach measurements. Dark adaptation was considered to be prolonged if return of prebleach sensitivity occurred outside the range for normal subjects in the same decade of life.

\section{Results}

Twelve patients with age-related maculopathy, and visual difficulties at different levels of light are included in this study (Table 1; Figs 1-4). The median age was 76 years (range 54-86). There were seven men and five women. Three patients (Nos 1, 2, 6) reported that their vision decreased after several minutes in bright light or that they recovered their vision very slowly after exposure to bright light, often preferring to avoid going out of doors on bright, sunny days. Seven patients (Nos 3-5, 8, 9, 11, 12) had good vision in daylight and greater difficulties in poor illumination. The remaining two patients (Nos $7,10)$ noted poor vision in both bright light and in the dark preferring intermediate light levels. Five (Nos 3, 5, 9, 10, 12) described a central scotoma that began early in dark adaptation.

The study eye of every patient had $6 / 12$ or better vision, and 10 of 12 patients had $6 / 9$ or better acuity. All were phakic without optically significant nuclear sclerosis on biomicroscopy. All patients had macular drusen in the study eye, and one (No 4) also showed a diffuse yellow

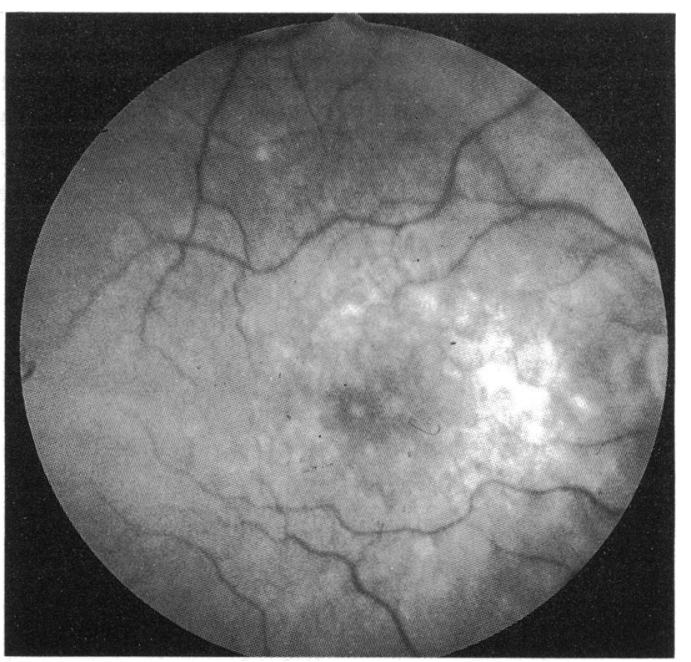

Figure 1 (A) Case 3. A 76-year-old woman noticed a central scotoma at night that began shortly after the lights were extinguished. Visual acuity was 6/9. The drusen were most prominent between the fovea and optic nerve. Table 2 Dark adaptation results. Cases 5 and 8 had sensitivities which were too poor to
undertake dark adaptation. The retinal coordinates refer to the degrees of visual angle from text for calculation of time constants

\begin{tabular}{|c|c|c|c|c|c|c|}
\hline Case & $\begin{array}{l}\text { Retinal } \\
\text { coordinate }\end{array}$ & $\begin{array}{l}\text { Scotopic } \\
\text { sensitivity }\end{array}$ & $\begin{array}{l}\text { Rod/cone } \\
\text { break }\end{array}$ & $\begin{array}{l}\text { Recovery } \\
\text { time }\end{array}$ & $\begin{array}{l}\text { Time constant } \\
\text { Cone }\end{array}$ & $\operatorname{Rod}$ \\
\hline 1 & \multirow{19}{*}{$\begin{array}{c}9,9 \\
9,-9 \\
9,9 \\
9,-9 \\
9,9 \\
9,-9 \\
15,15 \\
15,-15 \\
9,9 \\
-9 \cdot 3 \\
-3,9 \\
-3,3 \\
9,9 \\
3,3 \\
9,9 \\
-9,-15 \\
9,9 \\
3,--3 \\
-9,9 \\
3,-3\end{array}$} & \multirow{19}{*}{$\begin{array}{l}47 \\
44 \\
45 \\
42 \\
18 \\
40 \\
43 \\
42 \\
43 \\
35 \\
39 \\
34 \\
41 \\
33 \\
35 \\
19 \\
41 \\
38 \\
33 \\
26 \\
35-46\end{array}$} & \multirow{19}{*}{$\begin{array}{l}36 \\
31 \\
28 \\
32 \\
32 \\
32 \\
20 \\
20 \\
25 \\
25 \\
10 \\
23 \\
19 \\
30 \\
21 \\
21 \\
35 \\
38 \\
28 \\
85 \\
10-18\end{array}$} & \multirow{19}{*}{$\begin{array}{c}70 \\
76 \\
6 \dagger \\
6 \dagger \\
70 \dagger \\
70 \dagger \\
65 \dagger \\
65 \dagger \\
40 \\
42 \\
52 \\
70 \ddagger \\
40 \\
70 \ddagger \\
45 \\
50 \\
88 \\
90 \dagger \\
72 \\
114 \\
38-55\end{array}$} & 4.3 & $76 \cdot 5$ \\
\hline 2 & & & & & $\begin{array}{l}2 \cdot 2 \\
3 \cdot 0\end{array}$ & $\begin{aligned} & 44 \cdot 7 \\
> & 100\end{aligned}$ \\
\hline & & & & & $3 \cdot 2$ & $>100$ \\
\hline 3 & & & & & $6 \cdot 5$ & $<100$ \\
\hline & & & & & 3.5 & $<100$ \\
\hline 4 & & & & & $2 \cdot 7$ & $<100$ \\
\hline & & & & & $6 \cdot 2$ & $<100$ \\
\hline 6 & & & & & $2 \cdot 1$ & $10 \cdot 2$ \\
\hline & & & & & $2 \cdot 5$ & $25 \cdot 0$ \\
\hline 7 & & & & & $\begin{array}{l}1.6 \\
4.2\end{array}$ & $21 \cdot 4$ \\
\hline 9 & & & & & 3.8 & $\begin{array}{r}21.4 \\
9.0\end{array}$ \\
\hline & & & & & $2 \cdot 5$ & $31 \cdot 4$ \\
\hline 10 & & & & & $5 \cdot 3$ & $5 \cdot 2$ \\
\hline & & & & & 5.9 & 5.8 \\
\hline 11 & & & & & 2.9 & $8 \cdot 1$ \\
\hline & & & & & $3 \cdot 3$ & $85 \cdot 8$ \\
\hline 12 & & & & & $7 \cdot 2$ & $16 \cdot 4$ \\
\hline & & & & & & \\
\hline Normals & & & & & $0.9-1.9$ & $5 \cdot 4-15 \cdot 2$ \\
\hline
\end{tabular}

^ Goldmann size V stimulus; † Still elevated by $<0.5 \log$ units; $¥$ Still elevated by $<1.0$ log units. 

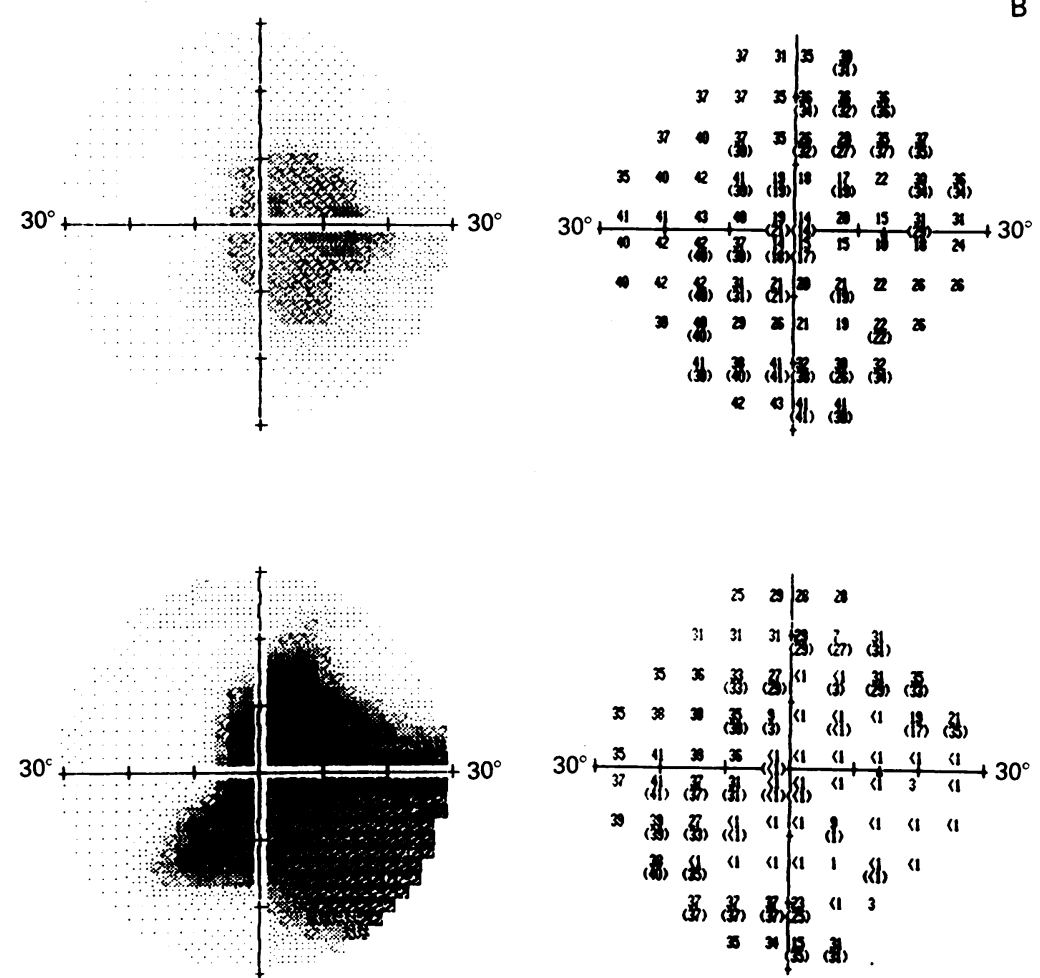

Figure 1 (B) The scotopic threshold was decreased by two log units $(20 \mathrm{~dB})$ over an area which encompassed both the fovea and optic nerve (top). Further threshold elevation and enlargement of the affected area 9 months later (bottom) (normal 35-46 dB).

Figure 1 (C) Dark adaptation measured at locations $9^{\circ}, 9^{\circ}(\mathrm{O})$ and $-9^{\circ}, 9^{\circ}()^{\prime}$ show an abnormal cone time constant, a delayed rod cone break, and a prolonged rod time constant, with retinal sensitivity still elevated by 10-15 dB after 65 minutes. The small triangles represent normal values at similar locations.

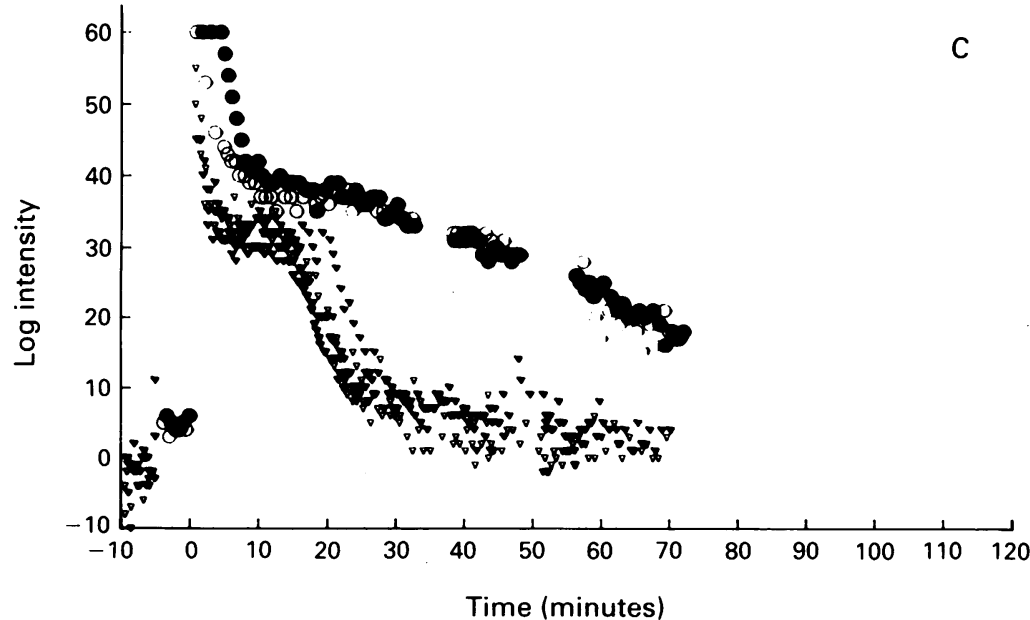
(Nos 5, 6, 8, 10, 11) which were within the normal reference range.

The dark adapted foveal threshold was variable, ranging from 1 to $24 \mathrm{~dB}$ above normal

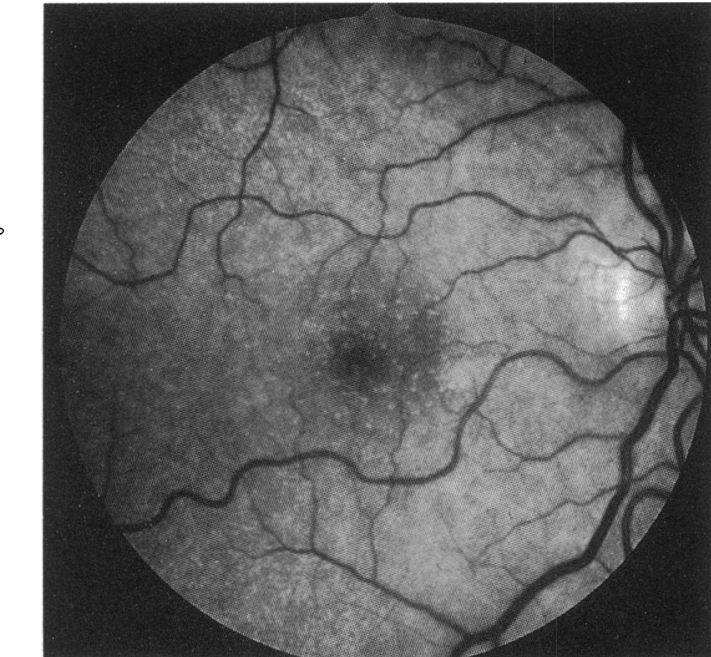

Figure 2 (A) Case 4. A 54-year-old man complained of poor night vision and difficulty when passing from light to dark. Visual acuity with the study eye was 6/6. Fine drusen and $a$ pale yellow diffuse fundus reflex at the level of Bruch's membrane present in both eyes.

values(Table 2, Figs 1-4). The scotopic threshold in the central $30^{\circ}$ was depressed by at least $10 \mathrm{~dB}$ in at least some locations in six patients (Nos 3, 5 , $8,9,10,12)$. Mesopic threshold perimetry did not suggest selective involvement of either the rod or the cone system. These patients reported poor vision in dim illumination or a central scotoma in the dark.

Reliable data on the time course of dark adaptation were obtained in 10 of 12 patients. Subjects 5 and 8 had up to $30 \mathrm{~dB}$ threshold elevations on scotopic perimetry and dark adaptation data were unreliable. The time to the return of prebleach sensitivities exceeded the range for our comparison group in nine of 10 cases (Table 2, Figs 1C, 2D, 3C, 4C). In eight (Nos $1-4,7,9,11,12)$ at least one location tested had not returned to initial threshold 60 minutes after light adaptation (Figs 1C, 2D). The time constant of rod sensitivity recovery was abnormal in at least one location in nine patients. In three of these (Nos 2-4) there was a slow drift-like

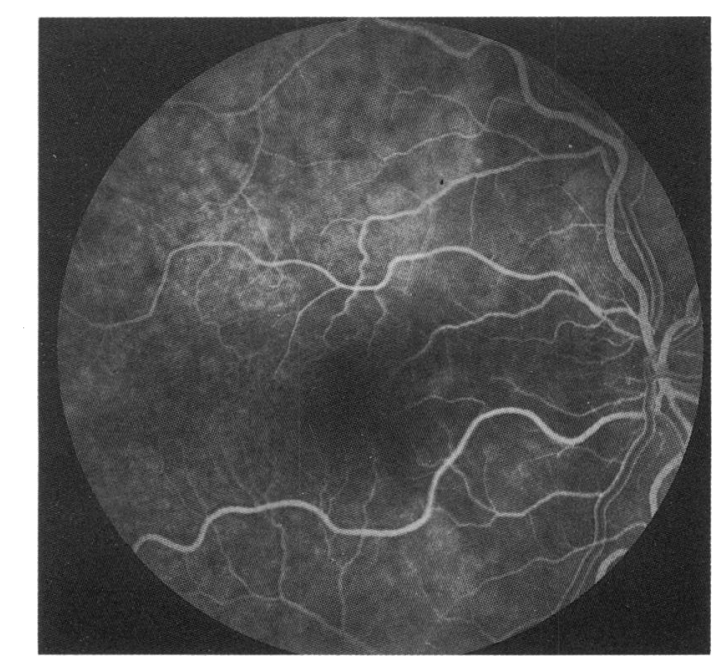

Figure 2 (B) Fluorescein angiography shows a prolonged choroidal filling phase, diffuse Bruch's membrane staining. The drusen remain hypofluorescent throughout the study. 

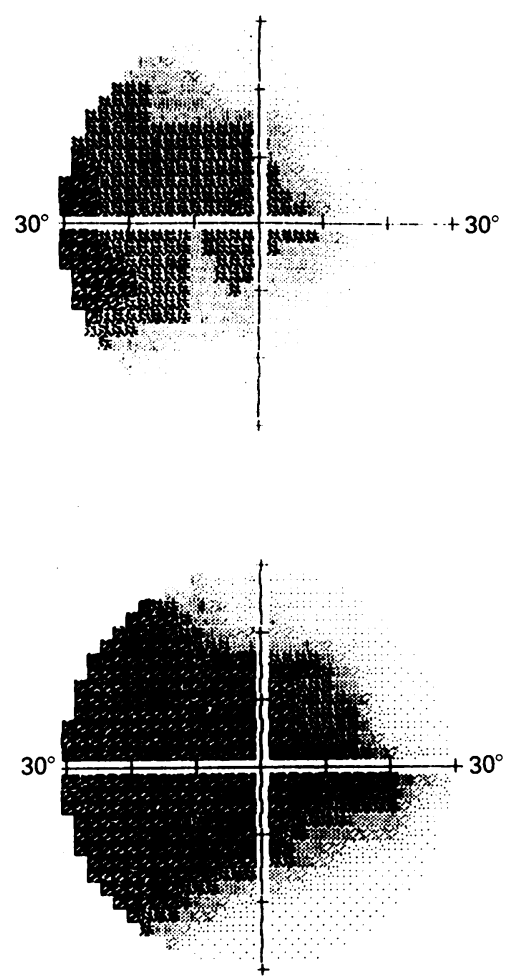

Figure 2 (C) Dark adapted static perimetry shows 25-30 dB threshold elevations in the temporal macula which corresponded to the area of prolonged choroidal filling (top). The scotoma is larger and the threshold further elevated 1 year later (bottom).

Figure 2 (D) Dark adaptation curves obtained from locations with normal prebleach sensitivity $\left(15^{\circ}, 15^{\circ} / 15^{\circ},-15^{\circ}\right)$ show an abnormal cone portion, $a$ rod cone break at 20 minutes, and a prolonged rod portion with retinal sensitivity still elevated $10 \mathrm{~dB}$ above prebleach values at 65 minutes. The small triangles represent normal values at similar locations.

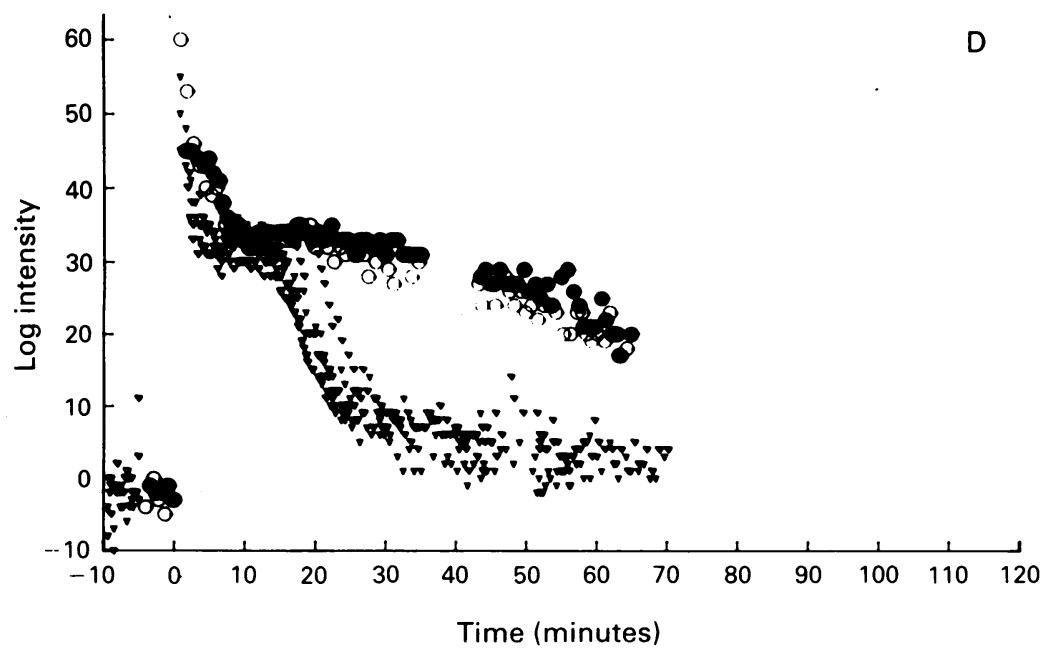
kinetics of dark adaptation varied from one patient to another. Six patients had normal dark adapted static perimetry with abnormal dark adaptation kinetics (Nos 1, 2, 6, 7, 9, 11) and in four (Nos 3, 4, 10, 12) both the dark adapted thresholds and the time course of dark adaptation were abnormal. The rod and cone time constants were prolonged both in locations where recovery of sensitivity was full and in areas with a decreased
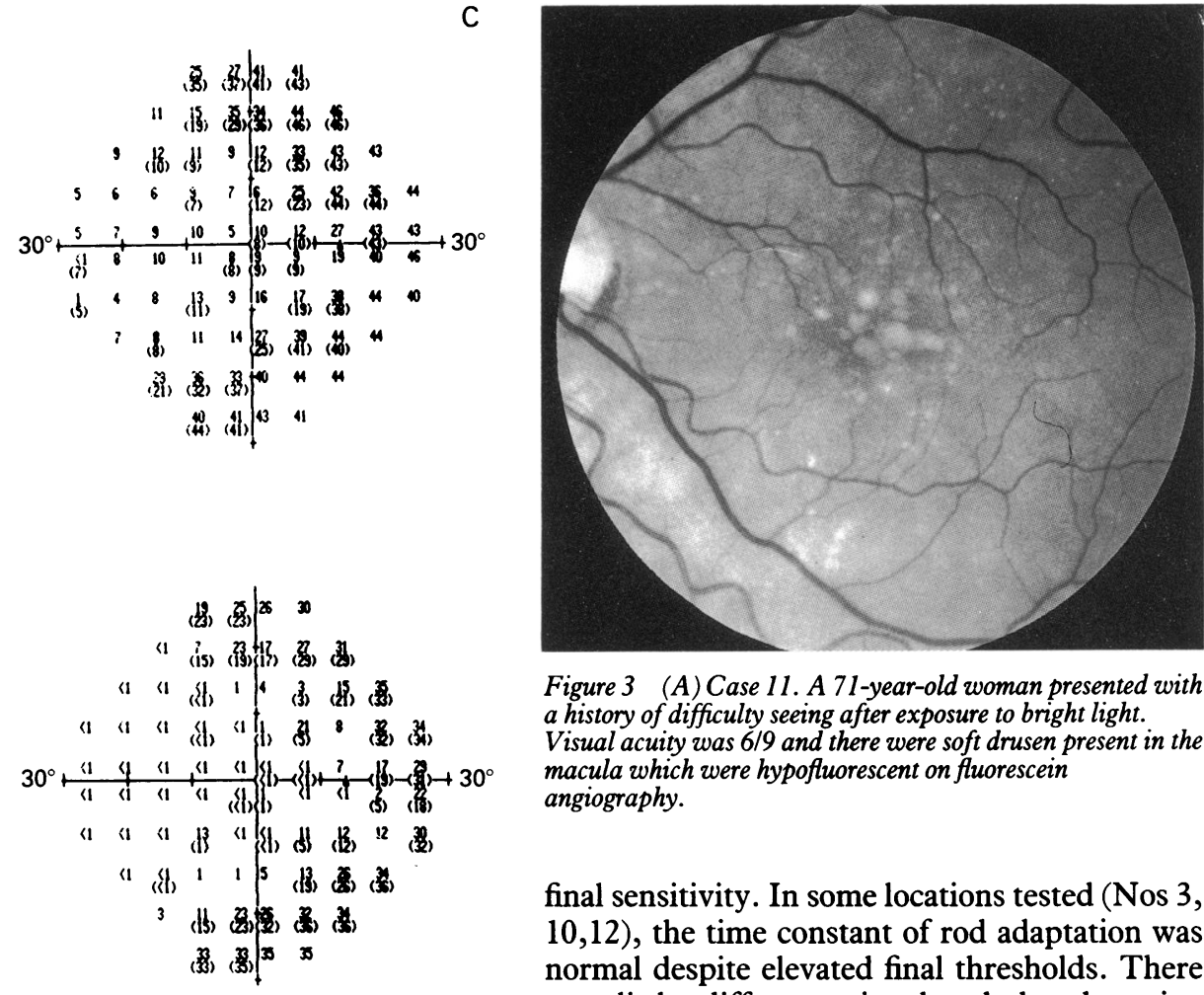

Figure 3 (A) Case 11. A 71-year-old woman presented with a history of difficulty seeing after exposure to bright light.

Visual acuity was 6/9 and there were soft drusen present in the macula which were hypofluorescent on fluorescein angiography.

final sensitivity. In some locations tested (Nos 3, 10,12 ), the time constant of rod adaptation was normal despite elevated final thresholds. There was little difference in the dark adaptation measurements between Goldmann size III and size $\mathrm{V}$ stimuli other than the expected offset due to neural summation ${ }^{16}$ (Fig $3 \mathrm{C}$ ).

In two patients increasing deficit was recorded over time although there was no change in visual acuity (Figs 1B, 2C).

Correlation between the clinical characteristics and the psychophysical results are illustrated in Figures 1-4. spection. In some locations, only the cone time constant was elevated (Nos 3, 6, 9-12), whereas in other locations both the rod and cone time constants were prolonged (Nos $1-4,6,7,9,11$, 12) (Table 2).

The relationship of scotopic sensitivity to the

\section{Discussion}

The visual symptoms reported by our patients with age-related maculopathy appear to be due to loss of visual function which can be readily revealed by scotopic perimetry and measurement of dark adaptation. Areas of diminished scotopic sensitivity in the central retina could be reliably mapped with the Humphrey field analyser, were often quite sharply demarcated, and, in general, corresponded well with the patients' subjective deficit. The functional losses were generally more impaired at locations closer to the fovea. These defects may occur in patients with excellent visual acuity and unremarkable fundus changes, and may cause significant handicap in life.

The cause of abnormal function in the absence of complications of Bruch's membrane change is unknown. Mild metamorphopsia and decreased reading ability especially in dimmed illumination, has been recognised in patients with extensive drusen centrally. ${ }^{17}$ Eyes with extensive drusen and hyperpigmentation may have reduced macular sensitivity especially if the fellow eye has exudative age-related maculopathy. However, it is unlikely that the symptoms reported by our patients could be explained by the drusen alone. There is no good relationship between the extent of drusen and the absolute threshold, ${ }^{5}$ is and the retinal sensitivity over a drusen is not depressed compared with adjacent non-drusen 

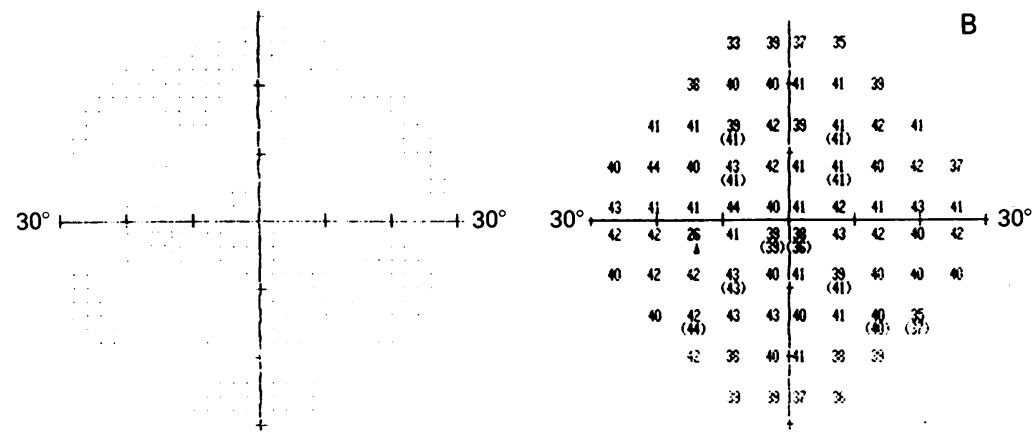

Figure 3 (B) Scotopic thresholds were normal.

Figure 3 (C) Dark adaptation curves obtained from location $3^{\circ},-3^{\circ}$ showed a markedly delayed rod cone break ( 38 minutes), and a prolonged rod portion with retinal sensitivity still elevated $5 d B$ above the prebleach value at 90 minutes. $(\mathrm{O}$, size III; size $V ; \circ$, normal III,$\bullet$, normal $V$ ).

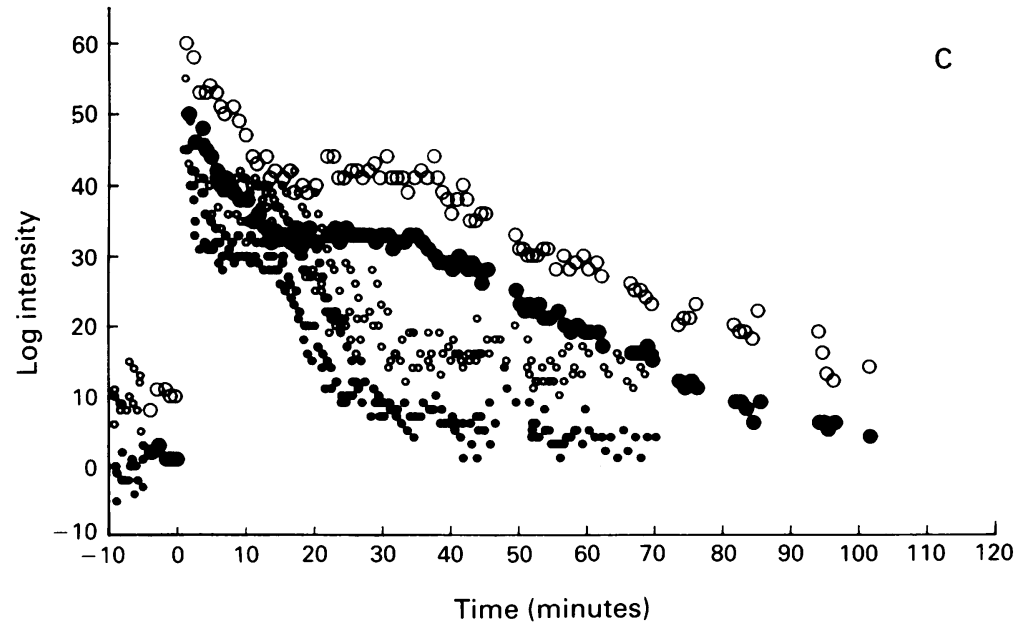

areas. ${ }^{19}$ Finally, in our study drusen were quite prominent in some patients but were relatively inconspicuous in others, but there was no correlation between the quantity of drusen and the nature or severity of the functional deficit.

One explanation for the functional disturbance was derived from observations in Sorsby's fundus dystrophy. Admittedly the concepts are unproved, but they are based on several pieces of circumstantial evidence. In Sorsby's fundus dystrophy a layer of material up to $30 \mu \mathrm{m}$ thick appears in the inner portion of Bruch's membrane. ${ }^{20}$ Patients with Sorsby's fundus dystrophy may have visual difficulties under different light levels similar to the symptoms recorded in the current study. Furthermore, psychophysical studies show up to $30 \mathrm{~dB}$ losses in scotopic sensitivity, and prolongation of dark adaptation before there is any compromise of visual acuity. ${ }^{21}$ It was suggested that this abnormal material may form a barrier to diffusion between the choroid and retinal pigment epithelium, and that the functional deficits are due to lack of metabolic supply to the outer retina. Predictably, a homologous situation would exist in age-related macular disease due to thickening of Bruch's membrane, ${ }^{1522} 23$ and the physiological disturbance would be greater if Bruch's membrane contained high levels of neutral lipids causing it to become hydrophobic. ${ }^{24}$ The observation of wide variation in both the total quantity of lipids and the ratio of phospholipids and neutral lipids in Bruch's membrane from elderly donors is compatible with this concept. $^{24-26}$ In some eyes this material is deposited as a diffuse layer rather than as discrete

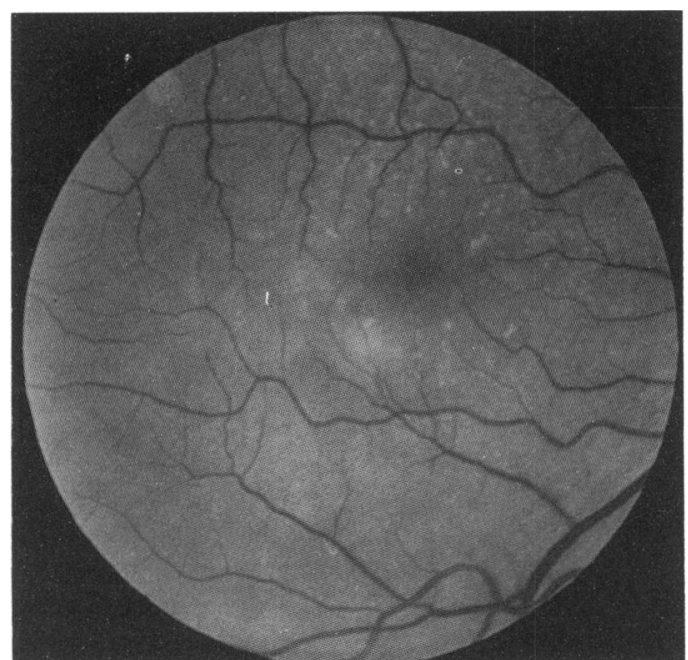

Figure 4 (A) Case 12. An 80-year-old man presented with a history of seeing a 'central black patch' in the dark and complaining of slow return of vision after exposure to bright light. Visual acuity was $6 / 9$ and there were soft drusen present in the macula.

deposits which may impair metabolic exchange between the retinal pigment epithelial cell and the choroidal capillaries. Two additional characteristics of the eyes included in this study support this view. There is evidence that a high content of neutral lipids is indicated by the presence of hypofluorescent drusen ${ }^{25}$; in nine of the 11 patients in whom fluorescein angiography was available the drusen did not fluoresce. It has been suggested that a barrier to metabolic exchange is implied by abnormal filling of the choriocapillaris on angiography ${ }^{27}$; six of our patients had this angiographic sign.

The pattern of visual loss recorded in our patients is in some ways similar to that seen in vitamin A deficiency, in which dark adaptation is prolonged initially but in which cone function is spared and final scotopic thresholds are normal..$^{29}$ The lack of systemic vitamin A deficiency does not exclude a localised shortage of vitamin A caused by impaired exchange across Bruch's membrane.

Alternatively, it is possible that progressive metabolic impairment of the pigment epithelium may result from accumulation of intracellular lipofuscin which occurs with age..$^{30-34} \mathrm{~A}$ similar situation exists in fundus flavimaculatus ${ }^{35}$ in which functional deficit is similar to that recorded in our patients, although the rod cone break and early portion of rod adaptation are preserved. ${ }^{36}$

The relationship between the scotopic threshold, rod cone break, and the time course of dark adaptation varied from one patient to another implying that there may not be a uniform progression of disease. The variability of these results suggests that they represent either different stages of the single sequence of events or reflect different structural or metabolic abnormalities at the level of the photoreceptor cells. In these subjects the photoreceptor outer segments may be reduced in volume, there may be reduction of the number of photoreceptor cells, abnormality of outer segment structure, or increased regeneration time of rhodopsin. Predictably, each of these would give rise to different combinations of functional defects. 

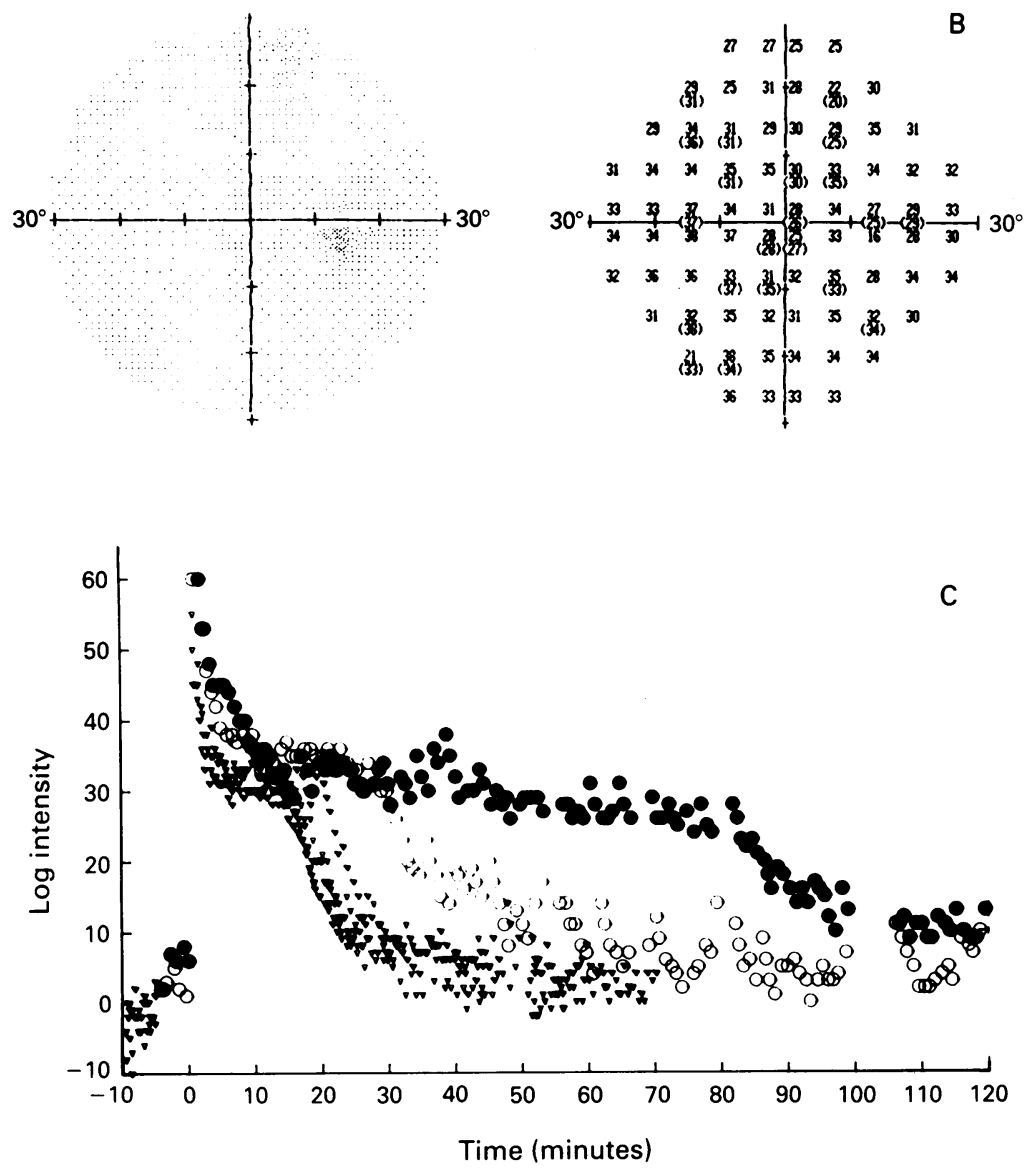

Figure 4 (B) (Scotopic perimetry showed scattered threshold elevation of up to $10 \mathrm{~dB}$. (C) Dark adaptation curves from location $-9^{\circ}, 9^{\circ}$ (O) shows delayed cone adaptation, a markedly delayed rod cone break, and recovery of to within $5 \mathrm{~dB}$ of prebleach sensitivities at 72 minutes. At location, $3^{\circ}$

$-3^{\circ}$, (O) the cone portion was delayed, the rod cone break was markedly delayed, and the rod portion had not returned to within $5 \mathrm{~dB}$ of pre-bleach sensitivities until 114 minutes.
Whether these reflect different disease mechanisms, or different reactions to a similar pathological process is not evident.

Long term review of our patients will be required to determine whether or not these functional abnormalities imply a higher risk of vision threatening complications of age-related maculopathy.

This work was supported by grants from The Wolfson Foundation, the Wellcome Trust, and the Medical Research Council of the UK.

1 Genensky SM, Berry SH, Bikson TH, Bikson TK. Visual environmental adaptation problems of the partially sighted final report (\#CPS-100-HEW). Center for the partially sighted, Santa Monica Hospital Medical Center, January

2 Campbell C, Rittler MC. Clinical adaptation studies of the human retina. In: Straatsma BR, Hall MO, Allen RA Crescitelli F, eds. The retina. Morphology, function and clinical characteristics. Berkeley: University of Californa Press, 1968: 513-44.

3 Brown B, Kitchin JL. Dark adaptation and the acuity/ luminance response in senile macular degeneration (SMD) Am 7 Optom Physiol Optics 1983; 60: 645-50.

4 Brown B, Adams AJ, Coletta NJ, Hagerstrom-Portnoy G Dark adaptation in age-related maculopathy. Ophthalmic Physiol Opt 1986; 6: 81-4.

5 Eisner A, Fleming SA, Klein ML, Mauldin MW. Sensitivities in older eyes with good acuity: eyes whose fellow eye has exudative age-related macular degeneration. Invest Ophthalmol Vis Sci 1987; 28: 1832-7.

6 Eisner A, Stroumbos VD, Klein M, Fleming SA. Relations between fundus appearance and function; eyes whose fellow eye has exudative age-related macular degeneration. Invest Ophthalmol Vis Sci 1991; 32: 8-20.

7 Morrison SA, Russell RM, Carney EA, Oaks EV. Zinc deficiency: a cause of abnormal dark adaptation. $\mathrm{Am} \mathcal{f} \mathrm{Clin}$ Nutr 1978; 31: 276-81.

8 Herlong HF, Russell RM, Maddrey, WC. Vitamin A and zinc therapy in primary biliary cirrhosis. Hepatology 1981; 1 : 348-51.

9 Russell RM, Smith VC, Multack R, Krill AE, Rosenberg IH Dark adaptation for diagnosis of subclinical vitamin A deficiency and evaluation of therapy. Lancet 1973; ii: 11614.

10 Dutta SK, Russell RM, Lakhanpal V. Abnormal dark adaptation in adult patients with protein-energy malnutrition: correction by protein-energy repletion. Nutr Res 1981; 1 : 443-9.

11 Warth JA, Prasad AS, Zwas F, Frank RN. Abnormal dark adaptation in sickle cell anaemia. $\mathcal{F}$ Lab Clin Med 1981; 98: 189-94.

12 Jacobson SG, Voight W, Parel JM, Apathy PP, Nghiew-Phy L, Myers SW, et al. Automated light and dark adapted perimetry for evaluating retinitis pigmentosa. Ophthalmology 1986; 93: 1604-11.

13 Chen JC, Fitzke FW, Pauleikhoff D, Bird AC. Functional loss in age-related Bruch's membrane change with choroida perfusion defect. Invest Ophthalmol Vis Sci 1992; 33: 334-9.

14 Pugh EN Jr. Rushton's paradox: rod dark adaptation after flash photolysis. F Physiol 1975; 248: 413-31.

15 Chuang EL, Bird AC. The pathogenesis of tears of the retina pigment epithelium. Am f Ophthalmol 1988; 105: 185-90.

16 Arden GB, Weale RA. Nervous mechanisms and dark adaptation. F Physiol 1954; 125: 417-26.

17 Gass JDM. Steroscopic atlas of macular diseases. 3rd ed. St Louis: Mosby, 1987: chap 3.

18 Sunness JS, Massof RW, Johnson MA, Finkelstein D, Fine SL. Peripheral retinal function in age-related macular degeneration. Arch Ophthalmol 1985; 103: 811-6.

19 Sunness JS, Johnson MA, Massof RW, Marcus S. Retinal sensitivity over drusen and nondrusen areas. A study using fundus perimetry. Arch Ophthalmol 1988; 106: 1081-4.

20 Capon MRC, Marshall J, Krafft JI, Alexander RA, Hiscott PS, Bird AC. Sorsby's fundus dystrophy. Ophthalmology 1989; 96: 1769-77.

21 Steinmetz R, Polkinghorne PC, Fitzke FW, Kemp CM, Bird AC. Abnormal dark adaptation and rhodopsin kinetics in Sorsby's fundus dystrophy. Invest Ophthalmol Vis Sci 1992; 33: $1633-6$.

22 Sarks SH. Ageing and degeneration in the macular region. A clincio-pathological study. Br F Ophthalmol 1976; 60: 324 41.

23 Bird AC, Marshall J. Retinal pigment detachments in the elderly. Trans Ophthalmol Soc UK 1986; 105: 674-82.

24 Pauleikhoff D, Harper CA, Marshall J, Bird AC. Aging changes in Bruch's membrane: a histochemical and morphological study. Ophthalmology 1990; 97: 171-8.

25 Pauleikhoff D, Zuels S, Sheraidah G, Marshall J, Wessing A, Bird AC. Determinants of the fluorescence of drusen in Bruch's membrane. Ophthalmology 1992; 99; 1548-53.

26 Sheraidah G, Steinmetz R, Maguire J, Pauleikhoff D, Marshal J, Bird A. Correlation between lipids extracted from Bruch's membrane and age. Ophthalmology, in press.

27 Pauleikhoff D, Chen JC, Chisholm IH, Bird AC. Choroida perfusion abnormalities in age related macular disease. $A m \mathcal{J}$ Ophthalmol 1990; 109: 211-7.

28 Chen J, Fitzke F, Pauliekhoff D, Bird AC. Functional loss in age-related Bruch's membrane change with choroida perfusion defect. Invest Ophthalmol Vis Sci 1992; 33: 334 40.

29 Streeten BW. The sudanophilic granules of the human RPE. Arch Ophthalmol 1961; 66: 125-32.

30 Wing GL, Blanchard GC, Weiter JJ. The topography and age relationship of lipofuscin concentration in the retinal pigrelationship of lipofuscin concentration in the retinal pig-

31 Weale RA. Do years or quanta age the retina? Photochem Photobiol 1989; 50: 429-38.

32 Boulton M. Ageing of the retinal pigment epithelium. In Osborne NN, Chader GJ, eds. Progress in retinal research. Vol 11. Oxford: Pergamon Press, 1991: 125-52.

33 Wyszynski RE, Brunar WE, Cano DB, Morgan KM, Davis CB, Sternberg P. A donor age-dependent change in the activity of alpha-mannosidase in human cultured RPE cells. Invest Ophthalmol Vis Sci 1989; 30: 2341-7.

34 Eagle RC, Lucier AC, Bernadino VB Jr, Yanoff $M$. Retina pigment epithelial abnormalities in fundus flavimaculatus: a light and electron microscopic study. Ophthalmology 1980; 87: 1189-200.

35 Fishman GA, Farbman JS, Alexander KR. Delayed rod dark adaptation in patients with Stargardt's disease. Ophthalmology 1991; 98: 957-62.

36 Kemp CM, Jacobson SG, Faulkner DJ, Walt RW. Visua function and rhodopsin levels in humans and vitamin $A$ deficiency. Exp Eye Res 1988; 46: 185-97. 